Boise State University ScholarWorks

Educational Technology Faculty Publications and

Presentations

Department of Educational Technology

11-28-2012

\title{
Technology-Supported Storytelling (TSST) Strategy in Virtual World for Multicultural Education
}

Jie Huang

Boise State University

Youngkyun Baek

Boise State University

Jungwon Cho

Jeju National University 


\title{
Technology-Supported Storytelling (TSST) Strategy in Virtual World for Multicultural Education
}

\author{
Jie Huang ${ }^{1}$, Youngkyun Baek ${ }^{1}$, Jungwon $\mathrm{Cho}^{2, *}$ \\ ${ }^{1}$ Boise State University, USA \\ youngkyun.baek@gmail.com \\ ${ }^{2}$ Department of Computer Education, Jeju National University, S.Korea \\ jwcho@jejunu.ac.kr
}

\begin{abstract}
Learning culture through stories is an effective way for multicultural education, since stories are one of the most powerful and personal ways that we learn about the world. Storytelling, the process of telling stories, is a form of communication and a universal expression of culture. With the development of technology, storytelling emerges out of diverse ways. This study explores the storytelling in virtual worlds for multicultural education, and devises a TechnologySupported storytelling (TSST) strategy by examining and considering the characteristics of virtual worlds which could be incorporated into the storytelling, and then uses this strategy to teach Korean culture to students with different culture background. With this innovative TSST strategy in virtual world, this study expects to provide a guide to practice for teaching multicultural in digital era.
\end{abstract}

Keywords: Multicultural education, TSST.

\section{Introduction}

Learning culture through stories is an effective way for multicultural education, since "stories are one of the most powerful and personal ways that we learn about the world, stories have passed down from generation to generation through the family and cultural groups to which we belong" [1]. Storytelling is the process of telling stories, and is a form of communication through which people, communities and society at large relay messages, entertainment experiences and knowledge to others [2]. With the development of technology, storytelling emerges out of diverse ways [3].Social media, games, virtual world with their traits evolved different storytelling practices.

In this study, we are going to explore the storytelling in virtual worlds for multicultural education. According to the traits of virtual world which have great potential to involve learners in meaningful learning [4], incorporate meaningful educational recourses and

\footnotetext{
* Corresponding Author.
} 
curriculum goals with virtual worlds traits can "provide highly collaborative, immersive environments that promote interaction among students and with the instructor" [5]. Designing pedagogically driven quests, online role playing, synchronous and asynchronous interaction activities in virtual worlds can engage learners in educational activities [6][7]. Researchers predict virtual worlds will bring major changes to the current instructional paradigm just as the Internet did in the past [8]. Teaching and learning in virtual worlds such as Second Life requires a paradigm shift by educators, researchers, and learners who are involved in and should adapt to the new environment of teaching and learning [9][10].

Since storytelling is ideal strategy for cultural education, and according to uniqueness characteristics of storytelling in virtual worlds, thereby devising a storytelling strategy in virtual worlds with consideration of taking advantages of both traits of virtual world and storytelling to promote cultural education is significant. This study devises a storytelling strategy by examining and considering the characteristics of virtual worlds which could be incorporated into the storytelling, and uses this strategy to teach Korean culture to students with different cultural background.

\section{Theoretical Framework}

\subsection{Storytelling and Culture}

[11] provide the definition of storytelling is "the seemingly easy, spontaneous, intimate sharing of a narrative with one or many persons; the storyteller relates, pictures, imagines, builds what happens, and suggests characters, involving him- or herself and listeners in the total story-all manifested through voice and body".

One of essential characteristics of storytelling is its universal expression of culture [12].The contents of stories are "both highest and truest expression of its authentic national culture and the appropriate foundation of its national literature" [13]. Stories with the culture content have passed down from generation to generation, and have been used throughout history for teaching and learning [14].Storytelling was incorporated into education as a useful tool for curriculum planning [15], when stories are made part of the lesson plan, students can understand information better, and their interest and attention are held longer [16]. Therefore, Storytelling can be used as learning strategy for understanding different cultures. 


\subsection{Diversity of Storytelling}

There are many kinds of storytelling depends on different expression ways. Storytelling is a means of engaging students. Students are more likely to take responsibility for engaging in their own learning if they have participated in a dialogue [17].Telling a personal story is a common storytelling strategy to interest listeners and provide the foundation for development of resilience [18].Storytelling combined students' personal experiences with specific social studies content create an opportunity to validate each student in classroom and demonstrate comprehension of the content through the personal story [19]. Participants' stories can provide insights into their backgrounds and experiences, giving a greater understanding of them in context [18].

Since Web 2.0 has led to an explosion of user-generated content, storytelling emerge out of diverse ways [3]. Social media, games, virtual world with their traits evolved different storytelling practices. For example, visual storytelling is one of storytelling which creates visual stories. Writing a story visually means "creating a situation or a plot, selecting and mixing certain materials, and displaying visual narrative devices, which allow us to represent "the succession of events" [20]. Digital storytelling is prevalent storytelling in digital era which has emerged over the last few years as a powerful teaching and learning tool to engage both teachers and their students. [21] indicated that digital storytelling is meaningful technology-integrated approach for engaging student learning, students did well in their projects and their stories benefit from many pedagogical and technical attributes of digital stories. The teachers believed that digital storytelling could increase students' understanding of curricular content and they were willing to transform their pedagogy and curriculum to include digital storytelling.

\subsection{Storytelling in virtual worlds}

Storytelling in virtual worlds shares the common characteristics with both visual storytelling and digital storytelling regarding to using image, audio and video to deliver the story. However, because of the inherent traits of virtual worlds, storytelling in virtual worlds shows its own characteristics in some aspects.

Virtual worlds are computer-simulated online environments involved large numbers of people interact through avatars [22][23]. Virtual worlds are able to promote collaborative learning and social learning community [5][6]. Specifically three dimensional online virtual worlds within animated avatar and vivid life-like environment can motivate learners to engage in purposeful educational inquires and learning activities [24]. The virtual worlds create online social community, collaborative and self-paced learning environments, make it possible to develop situated understandings, effective social practices, powerful identity, shared values, and ways of thinking, and facilitate $21 \mathrm{st}$ century skills [7][25][26][27]. Storytelling in virtual worlds follows the same premise of digital storytelling, however, based on the above characteristics of virtual worlds, instead of creating a video, students create an experience or a space in which others can walk 
through their stories [28]. Students not only create a story, they also narrate the stories and experience the stories of their classmates. Students showed great motivation in creating and expressing their stories, is "ideal for collaboration between pupils, and that the pupils enjoy creating a story in which their peer can take part" [29]. Telling story though avatar, communicate with other avatar or virtual peer, students feels as if she or he is part of a simulated universe [30][31].Students can dramatize their stories and play as actor or actress with the support of emotion and gesture, stories can be dramatic express in virtual interactive senses [32].Therefore, storytelling in virtual worlds can gain its strength from the virtual immersion in the multi-sensorial universes. Another different aspect of storytelling in virtual worlds is that students are able to see the progress of their projects from start to finish. "Being able to see a work in progress creates a type of asynchronous social learning or modeling between students without direct person-to-person observation" [28].

\section{Method}

In this study, we devised a storytelling strategy in virtual world, named technologysupported storytelling (TSST) strategy, and then implied this strategy to conduct a multicultural education program for student with different culture background to learn Korea culture in Second Life virtual world. The whole project, blended of both face-toface and online, divided into five weeks. First week is face-to-face class about course orientation and access to virtual world--Second Life, while the rest of weeks are online. Teachers and students meet two hours each week. In all 35 students from South Korea participant in this study, 17 elementary students and 18 secondary students, among them 15 are female while 20 male, aged from 11 to 16 . They come from multicultural family with father are Korean, while mother are from different country, such as Japan, China, Mongolia, Philippine and Thailand. The description of their family background is shown in Fig.1.

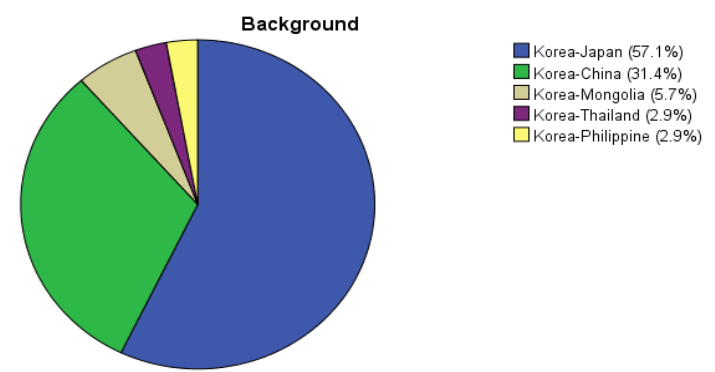

Fig. 1. Different culture background of participants 


\section{The technology-supported storytelling strategy (TSST)}

The technology-supported storytelling (TSST) strategy, shown in Figure 2, is constructed on Merrill's First Principles of Instruction [33] composed by five sequential principles, correspondingly the strategy contains five phases: Topic-centered: Learning content; Activation: Get involved; Demonstration: Begin a story; Application: Create your story and Integration: Perform your story. The whole project followed this strategy with careful instructional design integrated with culture content and learning activities in virtual world in order to support cultural education.

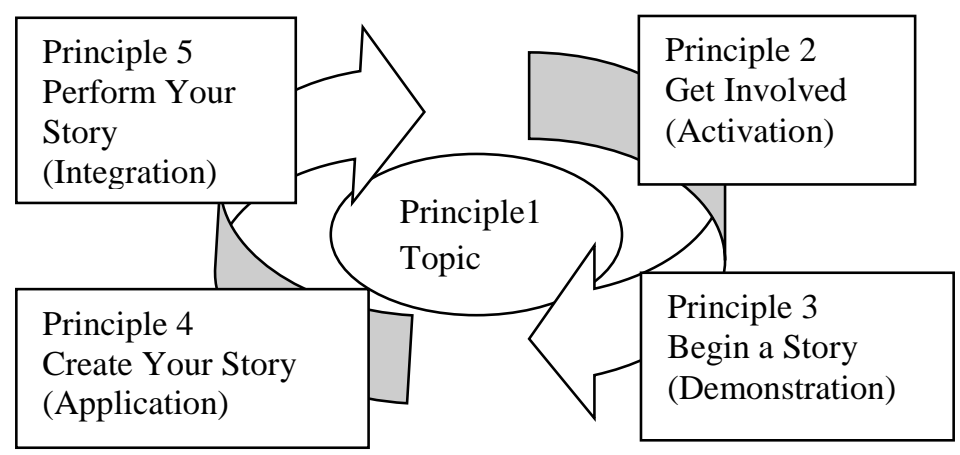

Fig. 2. Technology-supported Storytelling (TSST) Strategy

\section{Principle 1 Topic-centered: Learning content}

The whole process is concerned with the Topic. The topic could be the culture learning contents. The following learning processes are related to the central topic. In this phase, teacher can choose one culture topic as central contend to teach in the project. Korean traditional cloth- Hanbok was chosen as central topic in this study.

\section{Principle 2 Activation: Get involved}

Activation not only help students recall previous experience and provide relevant experience, but also stimulate mental models to be modified or tuned to enable students to incorporate the new knowledge into their existing knowledge. Teacher introduces storytelling strategy, guide students identify the characteristics of storytelling, understand the procedure of storytelling. Teacher introduces learning in virtual environment, motivate students to play and get familiar with the virtual learning environments

\section{Principle 3 Demonstration: Begin a story}

Learning is promoted when the instruction demonstrates what is to be learned and how to do. Knowledge to be learned exists at two levels: information and portrayal. Instruction is far more effective when it includes the portrayal level in that information, and demonstrates via specific situation or cases. Teacher demonstrates a story about the topic 
first. By doing this, the learning content is delivered, and also provides a model for student. In this way, teacher introduces storytelling in a nonthreatening situation, and shows a specific case of how to make a story in virtual world. In this study, teacher first told a story of Hanbok, which was the central cultural content. In this way, teacher not only taught content but also demonstrated how to tell a story for students.

\section{Principle 4 Application: Create your story}

Learning is promoted when students are required to use their new knowledge or skills to solve problem. Application phase is a necessary condition for effective learning. Let students to practice and doing learned knowledge and skills with appropriate feedback and coaching. This phase is divided into two sub-processes: Make an idea and develop the story. First, teacher list the central topic related terms, phrases, students pick up one term and make a sentence to describe the relationship between the term and central topic. The terms or relationship sentence will be the story idea which student will tell. The network of the central topic in this study shows in Fig 3. Teacher help students make an idea for their own stories, encourage students to blend their own experiences into the story, which is more effective way to learn and share cultural subject. Then, students discuss and revise their ideas according teacher and peer feedbacks, based on the characteristics and procedures of storytelling strategy and develop their story. Teacher provides technical supports, and error detection and correction.

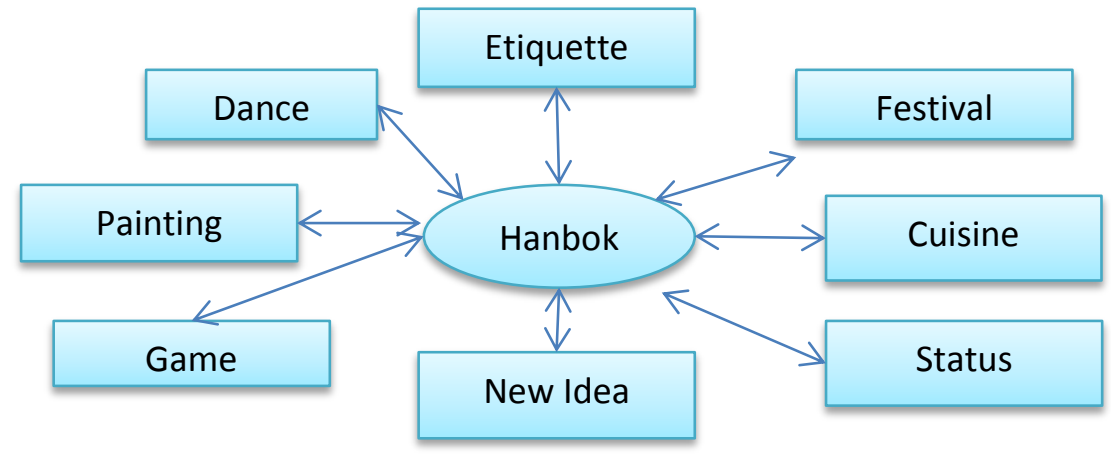

Fig. 3. The network of the cultural concept Hanbok

\section{Principle 5 Integration: Perform your story}

Learning is promoted when students can create, invent and explore new and personal ways to use their new knowledge or skills, and when they are given an opportunity to publicly demonstrate their new knowledge or skills, and when they can reflect on, discuss and defend their new knowledge or skills. In integration phase, students can take advantage of virtual world, use sceneries, objects, photographs, avatars, music to create their own story, and performance to other students. After storytelling provide them an opportunity to reflect on, defend, and share what they have learned. 


\section{Result}

During the one moth program in Second Life, students showed great interesting in learning Korean culture. Most students expressed that they can easily remember the content by listing and watching the stories teacher and peers demonstrated, they were engaged in exploring related stories to central topic and creating their own stories in virtual world, they viewed it a way to understand culture without threaten and pressure.

\section{Conclusion}

This study devises an innovative storytelling strategy- Technology-Supported Storytelling (TSST) Strategy for multicultural education, by taking advantages of the traits of virtual world, which serves as a guide to practice for teaching multicultural with virtual world, highlighting storytelling in virtual world can be used in different context with different central topics. This study will benefit to multicultural education in digital era.

\section{References}

1. Bell, L. A., Storytelling for social justice: Connecting narrative and the arts in antiracist teaching. New York: Routledge. (2010)

2. Bowles, N., Story telling: A search for meaning within nursing practice. Nurse Education Today, 15(5), 365--369 (1995)

3. Alexander, B., The new digital storytelling: Creating narratives with new media. Santa Barbara, Calif: Praeger. (2011)

4. Jonassen, D. H., Meaningful learning with technology. Columbus, OH: Merrill/Prince Hall. (2008)

5. Jones, J. G., 3D on-line distributed learning environments: An old concept with a new twist. In C. Crawford et al. (Eds.), Proceedings of the Society for Informational Technology and Teacher Education (pp. 507--512). Chesapeake, VA: Association for the Advancement of Computing in Education. (2004)

6. Barab, S., Thomas, M., Dodge, T., Carteaux, R., \& Hakan, T., Making learning fun: Quest Atlantis, a game without guns. Educational Technology Research and Development, 53(1), 86-107. (2005)

7. Dickey, M. D., Three-dimensional virtual worlds and distance learning: two case studies of active worlds as a medium for distance education. British Journal of Educational Technology, 36(5), 439---451. (2005)

8. Aldrich, C., Learning online with games, simulations, and virtual worlds. San Francisco, CA: Jossey-Bass. (2009)

9. Dede, C. J., The evolution of constructivist learning environments: immersion in distributed virtual worlds. Educational Technology, 35(5), 46--52. (1995) 
10. Smith, M. \& Berge, Z.L., Social learn $\neg$ ing theory in Second Life. Journal of Online Learning and Teaching, 5(2), 439--445. (2009)

11. Breneman, L. N., \& Breneman, B., Once upon a time: A storytelling handbook. Chicago: Nelson-Hall. (1983)

12. Carter-Black, J., Teaching cultural competence: An innovative strategy grounded in the universality of storytelling as depicted in African and African American storytelling traditions. Journal of Social Work Education, 43(1), 31--50. (2007)

13. Bauman, R., Story, performance, and event: Contextual studies of oral narrative. New York: Cambridge University Press. (1992)

14. Abrahamson, C. E., Storytelling as a pedagogical tool in higher education. Education, 118(3), 440-451. (1998)

15. Gudmundsdottir, S., Story-maker, story-teller: narrative structures in curriculum. Journal of Curriculum Studies, 23(3), 207--18. (1991)

16. Mason, H., The power of storytelling: A step-by-step guide to dramatic learning in K-12. Thousand Oaks, Calif: Corwin Press. (1996)

17. Miley, F., The storytelling project: innovating to engage students in their learning. Higher Education Research \& Development, 28(4), 357-369. doi:10.1080/07294360903046892 (2009)

18. East, L., Jackson, D., O'Brien, L., \& Peters, K., Storytelling: an approach that can help to develop resilience. Nurse Researcher, 17(3), 17--25. Retrieved from EBSCOhost. (2010)

19. Harris, R. B., Blending narratives: A storytelling strategy for social studies. Social Studies, 98(3), 111--116. (2007)

20. Rifà-Valls, M., Experimenting with visual storytelling in students' portfolios: Narratives of visual pedagogy for pre-Service teacher education. International Journal of Art \& Design Education, 30(2), 293-306. doi:10.1111/j.1476-8070.2011.01674.x (2011)

21. Sadik, A,. Digital storytelling: a meaningful technology-integrated approach for engaged student learning. Educational Technology Research and Development, 56(4), 487--506. (2008)

22. Bishop, J., Enhancing the understanding of genres of web-based communities: The role of the ecological cognition framework. Int. Journal of Web-Based Communities, 5(1), 4--17. (2009)

23. Bell, M., Toward a definition of "virtual worlds". Journal of Virtual Worlds Research. 1(1), 1-5. Retrieved from http://journals.tdl.org/jvwr/index (2008)

24. Cooke-Plagwitz, J., New directions in CALL: An objective introduction to Second Life. CALICO Journal, 25(3), 547--557. (2008)

25. Dalgarno, B., The potential of $3 \mathrm{D}$ virtual learning environments: a constructivist analysis. Electronic Journal of Instructional Science and Technology, 5(2), 1--19. (2002)

26. Dickey, M. D., Teaching in 3D: Pedagogical affordances and constraints of 3D virtual worlds for synchronous distance learning. Distance Education, 23(1), 105--121. (2003)

27. Shaffer, D. W., Squire, K. D., Halverson, R., \& Gee, J. P., Video Games and the Future of Learning. Phi Delta Kappan, 87(2), 104--111. (2005)

28. Sanchez, J., Pedagogical applications of Second Life. Library Technology Reports, 45(2), 21 -28. (2009)

29. Robertson, J., \& Good, J., Children's narrative development through computer game authoring. Techtrends, 49(5), 43--59. (2005)

30. Metros, S. E., The educator's role in preparing visually literate learners, Theory into Practice, 47(2), 102--109. (2008)

31. Ryokai, K., Vaucelle, C., \& Cassell, J., Virtual peers as partners in storytelling and literacy learning. Journal of Computer Assisted Learning, 19(2), 195--208. (2003)

32. Zagalo, N., \& Torres, A., Character emotion experience in virtual environments. The Visual Computer, 24(11), 981--986. (2008) 
This is an author-produced, peer-reviewed version of this article. The final publication is available at www.springerlink.com. Copyright restrictions may apply. DOI: 10.1007/978-3-642-35248-5_15

33. Merrill, D., First principles of instruction. Educational Technology Research and Development, 50(3), 43--59. (2002) 